\title{
Estimasi Spektrum Reflectance Citra Daun Jati Belanda Menggunakan Transformasi Wavelet
}

\section{Spectral Reflectance Estimation of Jati Belanda Leaf Images Using Wavelet Transformation}

\author{
I GEDE ARTA WIBAWA $^{1 *}$, YENI HERDIYENI ${ }^{1}$, BIB PARUHUM SILALAHI ${ }^{2}$
}

\begin{abstract}
Abstrak
Jati belanda (Guazuma Ulmifolia) adalah salah satu tanaman yang berkhasiat sebagai antioksidan karena pengaruh senyawa aktif yang terkandung di dalamnya. Cahaya pantulan (reflectance) dapat digunakan untuk mengetahui kualitas senyawa aktif pada daun jati belanda. Penelitian ini membahas tentang estimasi spektrum reflectance citra digital daun jati belanda menggunakan model reflectance daun tanaman obat dengan menerapkan transformasi wavelet. Bahan yang digunakan adalah daun tanaman obat dan daun jati belanda. Transformasi wavelet digunakan untuk merepresentasikan reflectance daun tanaman obat. Model polinomial diterapkan untuk mengekspansi ciri citra digital. Model reflectance terbaik dari penerapan transformasi wavelet dan model polinomial digunakan untuk mengestimasi reflectance dari daun jati belanda. Evaluasi spektrum reflectance asli dengan spektrum keluaran model estimasi reflectance menggunakan kriteria kesalahan terkecil dan kemiripan terbesar.
\end{abstract}

Kata kunci: jati belanda, model polinomial, reflectance, wavelet

\begin{abstract}
Jati belanda (Guazuma ulmifolia) is one of the plants is efficacious as an antioxidant because of the influence of the active compounds contained therein. Reflected light (reflectance) can be used to determine the quality of the active compounds in the jati belanda leaves. This study discusses the estimated reflectance spectrum of jati belanda leaf digital image using reflectance model of medicinal plants leaves by applying wavelet transform. The materials used are the leaves of herbs and jati belanda leaves. Wavelet transform is used to represent the medicinal plant leaf reflectance. Polynomial model is applied to expand the digital image characteristics. The best reflectance models of the application of wavelet transform and polynomial models are used to estimate the reflectance of jati belanda leaves. Evaluation of the the original and the estimation spectrum evaluated using the smallest error and the greatest similarity.
\end{abstract}

Keywords: jati belanda, polynomial model, reflectance, wavelet

\section{PENDAHULUAN}

Jati belanda (Gauzuma ulmifolia) adalah salah satu tumbuhan tropis yang dapat digunakan sebagai bahan baku pengobatan tradisional dan herbal. Batang jati belanda biasa digunakan sebagai bahan bangunan. Kulit dan daun mengandung berbagai macam senyawa aktif yang dapat digunakan untuk mengobati berbagai macam penyakit (George et al. 2001). Daun adalah tempat terjadinya proses fotosintesis atau penyerapan dan pemrosesan energi cahaya menjadi energi kimia untuk kelangsungan hidup tumbuhan. Klorofil dan karoten adalah pigmen penting pada proses fotosintesis. Proses fotosintesis menghasilkan berbagai senyawa aktif yang diperlukan oleh tumbuhan. Pigmen penting pada daun selain bertugas untuk menyerap energi cahaya juga berperan memberikan warna bagi tumbuhan.

${ }^{1}$ Departemen Ilmu Komputer, Fakultas Matematika dan Ilmu Pengetahuan Alam, Institut Pertanian Bogor, Bogor 2Departemen Matematika, Fakultas Matematika dan Ilmu Pengetahuan Alam, Institut Pertanian Bogor, Bogor *Penulis Korespondensi : Hp : 081904055609; Surel : gedearta83@gmail.com 
Kandungan senyawa aktif pada tanaman obat bervarisi. Faktor yang mempengaruhi kandungan senyawa aktif adalah: spesies, varietas, kondisi geografis, budidaya, metode pemanenan, proses pasca panen (Singh et al. 2010) dan usia (Anuradha et al. 2010). Semakin tua usia tanaman obat, kandungan senyawa aktif yang terkandung semakin besar sehingga usia dapat digunakan sebagai salah satu faktor penanda mutu tanaman obat (Anuradha et al. 2010). Usia tanaman dapat direpresentasikan melalui tingkat kecerahan atau warna daun sehingga warna daun dapat digunakan sebagai penanda kualitas senyawa aktif yang terdapat pada daun (Choudhary dan Sekhon 2011). Daun muda lebih cerah dibandingkan dengan daun yang lebih tua. Daun muda memiliki lebih sedikit senyawa aktif jika dibandingkan dengan daun tua. Daun muda memerlukan sedikit cahaya karena kandungan pigmennya sedikit, sehingga cahaya yang dibutuhkan daun muda lebih sedikit dari pada cahaya yang dipantulkan. Cahaya yang dipantulkan oleh suatu objek disebut dengan istilah reflectance (Herdiyeni et al. 2014).

Pada proses produksi massal obat herbal, kualitas dari bahan baku menjadi hal yang sangat penting untuk menghasilkan produk obat herbal yang baik. Proses pascapanen dengan umur daun yang berbeda dapat menyebabkan kualitas senyawa aktif tidak dapat dikontrol dengan baik. Metode kendali mutu diperlukan untuk memastikan kualitas bahan baku obat sehingga mampu berkhasiat bagi penggunanya (Kushwaha et al. 2010). Pengujian mutu dan kandungan senyawa pada tanaman obat pada umumnya dapat dilakukan dengan metode uji kimia kromatografi (Choudhary dan Sekhon 2011). Penerapan uji kimia kromatografi mempunyai efek samping yang dapat merusak objek penelitian, waktu yang relatif lama dan biaya yang relatif mahal. Metode alternatif uji kimia diperlukan untuk mengatasi kekurangan uji kimia.

Model reflectance dapat digunakan sebagai alternatif uji kimia untuk menentukan usia daun tanaman obat. Model reflectance telah diterapkan untuk menentukan usia daun Sambiloto (Herdiyeni et al. 2014). Metode yang digunakan adalah Wiener Estimation dengan akurasi mencapai $73.61 \%$. Estimasi reflectance pada daun jati belanda menggunakan transformasi Fourier menghasilkan nilai error dan Goodness of Fit Coefficient (GFC) sebesar 4.83 dan 0.96 (Lantana et al. 2014). Model reflectance juga diterapkan untuk mengestimasi reflectance pada citra lukisan (Mansouri et al. 2008). Metode yang digunakan adalah principle component analysis (PCA), transformasi Fourier, dan transformasi wavelet Haar. Transformasi wavelet memiliki performa yang lebih baik dari PCA dan transformasi Fourier (Mansouri et al. 2008).

Penelitian ini menggunakan transformasi wavelet dan menerapkan model polinomial untuk membentuk model reflectance sehingga mampu merepresentasikan reflectance daun jati belanda. Transformasi wavelet diterapkan untuk mencari dan merepresentasikan reflectance daun tanaman obat. Model polinomial diterapkan untuk menguji pengaruh penambahan ciri citra digital terhadap performa model reflectance. Model reflectance terbaik dipilih berdasarkan nilai root mean square error (RMSE) terkecil dan goodness of fit coefficient (GFC) yang terbesar untuk masing-masing wavelet dan model polinomial yang diterapkan.

\section{METODE}

Estimasi reflectance citra daun jati belanda menggunakan model reflectance tanaman obat terbaik dilakukan melalui 5 tahapan. Tahapan penelitian dapat dilihat pada Gambar 1.

\section{Akuisisi Data}

Data yang digunakan adalah data primer. Bahan dikumpulkan dari Unit Konservasi dan Budidaya Pusat Studi Biofarmaka LPPM IPB. Data diperoleh dari proses akuisisi 46 daun tanaman obat dan 10 daun jati belanda menggunakan spektrofotometer dan kamera digital. Spektrum reflectance diakuisisi menggunakan spektrofotometer. Hasil akuisisi spektrofotometer berupa nilai spektrum reflectance pada kisaran gelombang tampak dengan panjang gelombang 400-700 nm. Sampel spektrum berjumlah 515 pada setiap akuisisi. Setiap daun diakuisisi enam kali pada bagian bawah tulang daun, karena pada bagian tersebut tidak 
terjadi perubahan warna yang signifikan jika dibandingkan dengan bagian pinggiran daun. Setiap kali akuisisi spektrofotometer mewakili 1 buah titik pada daun.

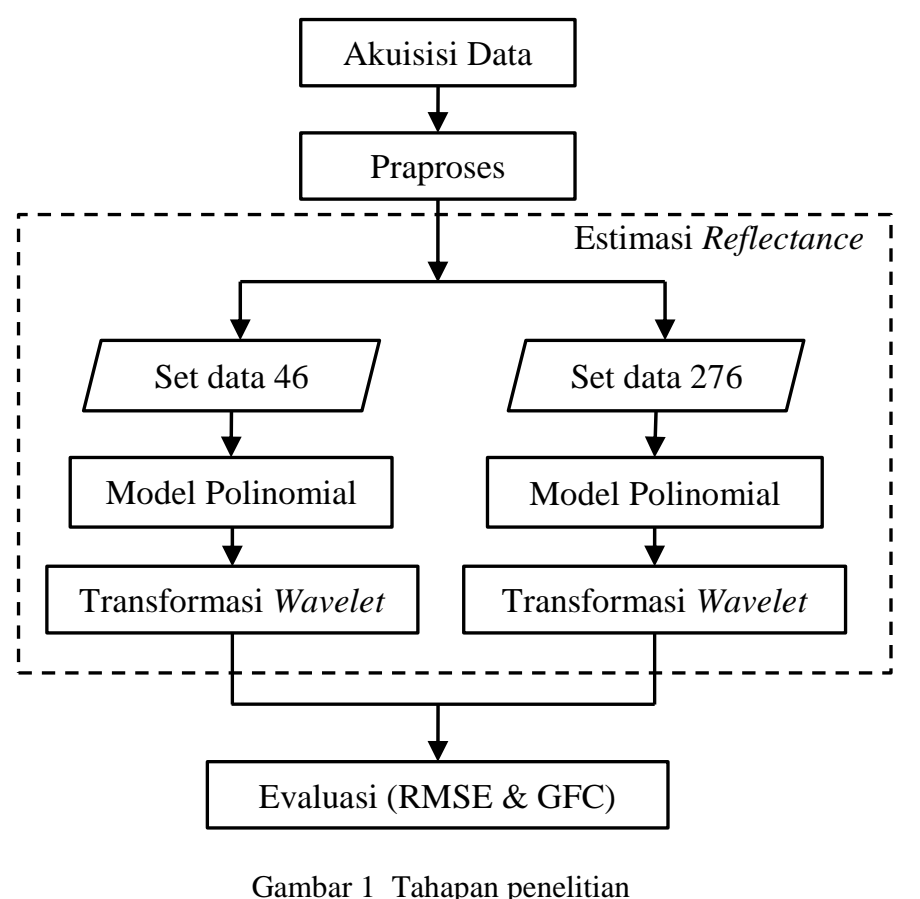

Data citra digital diperoleh menggunakan kamera digital dengan resolusi $8 \mathrm{MB}$. Akuisisi dilakukan di dalam kotak dengan lampu tungsten 15 watt sebagai sumber pencahayaan. Setiap daun diletakan di dalam kotak dengan latar belakang putih secara bergantian. Akuisisi citra daun dilakukan pada jarak $50 \mathrm{~cm}$ dan tegak lurus dari sumber cahaya. Pengambilan data dilakukan di dalam kotak supaya menghasilkan efek pencahayaan yang homogen dan terhindar dari efek cahaya luar yang tidak diinginkan. Setiap kali akuisisi menggunakan kamera digital mewakili sebuah wilayah pada daun.

\section{Praproses}

Data citra digital dilakukan pemotongan (cropping) manual pada wilayah yang sama dengan tempat pengambilan data reflectance. Ukuran citra hasil pemotongan ialah 100x100 piksel. Pada setiap citra, 6 buah piksel yang sesuai dengan titik pengambilan reflectance diambil. Proses akuisisi menghasilkan set data berukuran 276. Set data 46 diturunkan dari set data 276 melalui proses rata-rata sehingga setiap daun tanaman obat memiiki 1 buah spektrum reflectance dan 1 piksel dengan komponen warna merah, hijau dan biru. Set data 46 dan 276 digunakan sebagai data latih dan data citra 10 daun jati belanda sebagai data uji.

\section{Estimasi Spektrum Reflectance}

Estimasi spektrum reflectance menggunakan Persamaan 1 (Mansouri et al. 2008).

$$
r r=B\left(S^{T} B\right)^{-1} d_{u j i}
$$

dengan $r r$ adalah reflectance rekonstruksi atau nilai reflectance estimasi. $B$ adalah fungsi basis yang dihasilkan dari hasil transformasi reflectance data latih menggunakan wavelet. $S$ adalah sensitivitas kamera dan $d_{u j i}$ adalah matriks citra digital 10 daun jati belanda atau citra data uji. Sensitivitas kamera $S$ diperoleh menggunakan Persamaan 2 (Herdiyeni et al. 2014).

$$
S=d_{\text {latih }}{ }^{T} r
$$

dengan $r$ adalah matriks nilai reflectance data latih dan $d_{\text {latih }}$ adalah matriks citra dari data latih. $S$ diperoleh dengan perkalian matriks citra $d_{\text {latih }}$ dengan spektrum reflectance-nya. Operasi 
transpose ${ }^{T}$ diperlukan supaya perkalian matriks dapat dilakukan dan nilai $S$ dapat ditentukan. $B\left(S^{T} B\right)^{-1}$ adalah model reflectance daun tanaman obat yang digunakan untuk mengestimasi reflectance citra daun jati belanda $\mathrm{d}_{\mathrm{uji}}$.

\section{Model Polinomial}

Matriks $d_{l a t i h}$ dan $d_{u j i}$ diproses menggunakan model polinomial. Model polinomial digunakan untuk menambah ciri citra digital jati belanda. Penggunaan model polinomial bertujuan untuk menguji pengaruh penambahan ciri citra digital jati belanda terhadap performa model reflectance. Matriks $d_{l a t i h}$ dan $d_{u j i}$ di ekspansi menggunakan 3 ordo polinomial. Persamaan polinomial 3 orde dapat dilihat pada Tabel 1.

Tabel 1 Model polinomial

\begin{tabular}{rrl}
\hline Orde & Terms & Model Polinomial \\
\hline 1 & 3 & R G B \\
2 & 7 & R G B R $^{2} \mathrm{G}^{2} \mathrm{~B}^{2}$ RB \\
3 & 10 & R G B R $^{2} \mathrm{G}^{2} \mathrm{~B}^{2}$ RG RB GB RGB \\
\hline
\end{tabular}

\section{Transformasi Wavelet}

Transformasi wavelet adalah teknik yang digunakan untuk menganalisis sinyal melalui pergeseran dan perenggangan mother wavelet. Transformasi wavelet memiliki performa yang baik untuk menganalisis sinyal non periodik. Wavelet adalah sebuah gelombang pendek yang energinya terpusat pada interval waktu yang singkat. Transformasi wavelet dipakai pada pemrosesan sinyal dan pengolahan citra digital. Transformasi wavelet sangat tepat diterapkan untuk pemrosesan sinyal non-periodik (Lee dan Yamamoto 1994). Transformasi wavelet adalah pengembangan dari transformasi Fourier yang bekerja pada gelombang periodik (Sanjeevi et al. 2001). Transformasi wavelet mampu menyediakan informasi waktu dan frekuensi secara simultan.

Teknik subband coding digunakan untuk membentuk fungsi basis $B$. Transformasi wavelet dipandang sebagai sebuah fiter bank. Sinyal dilewatkan ke dalam filter bank. Hasil transformasi wavelet adalah koefisien frekuensi rendah $A_{j}$ dan koefisien frekuensi tinggi $D_{j}$ dimana $j$ adalah jumlah dekomposisi atau level transformasi wavelet. Koefisien frekuensi rendah dihasilkan oleh low pass filter (LPF) dan koefisien frekuensi tinggi dihasilkan oleh high pass filter (HPF) (Mallat 1989).

\section{Evaluasi}

Untuk mengevaluasi model reflectance digunakan model root mean square error (RMSE) dan goodness of fit coefficient (GFC). Reflectance asli dievaluasi dengan nilai reflectance estimasi daun jati belanda. Model RMSE mengevaluasi kedekatan jarak antara komponen sinyal pada setiap panjang gelombang melalui nilai error yang dihasilkan. Semakin kecil nilai error maka nilai sinyal estimasi semakin mendekati sinyal asli. Model GFC mengevaluasi kemiripan sinyal. Semakin besar nilai GFC maka kemiripan sinyal semakin besar. Formula RMSE dan GFC dapat dilihat pada Persamaan 3 dan Persamaan 4.

$$
\begin{gathered}
R M S E=\sqrt{\frac{\sum_{i=1}^{n}\left(s\left(\lambda_{i}\right)-s r\left(\lambda_{i}\right)\right)^{2}}{n}} \\
G F C=\frac{\left|\sum_{i=1}^{n} s\left(\lambda_{i}\right) \operatorname{sr}\left(\lambda_{i}\right)\right|}{\left(\left|\sum_{i=1}^{n}\left[s\left(\lambda_{i}\right)\right]^{2}\right|^{1 / 2}\right)\left(\left|\sum_{i=1}^{n}\left[\operatorname{sr}\left(\lambda_{i}\right)\right]^{2}\right|^{1 / 2}\right)}
\end{gathered}
$$

Nilai $s$ adalah spektrum original, $s r$ adalah spektrum rekonstruksi dari sebuah sinyal dengan panjang gelombang $\lambda_{i}, n$ jumlah kanal dan $i$ adalah indeks kanal dengan nilai 1 sampai $n$ jumlah kanal. 


\section{HASIL DAN PEMBAHASAN}

Evaluasi dilakukan dengan membandingkan hasil keluaran model estimasi reflectance dengan nilai reflectance asli dari daun jati belanda hasil pengukuran spektrofotometer. Transformasi wavelet menghasilkan komponen spektrum reflectance frekuensi rendah (LPF) dan spektrum reflectance frekuensi tinggi (HPF). HPF adalah filter yang menghasilkan efek kontras jika diterapkan pada citra digital. Pada citra kontras, terdapat perubahan yang besar antara piksel dan piksel yang lain. LPF menghasilkan citra halus/blur jika diterapkan pada citra digital.

Fungsi basis $B$ dipilih dari komponen spektrum reflectance frekuensi rendah karena pada panjang gelombang tampak (400-700 nm), perubahan warna terjadi secara perlahan yang sesuai dengan sifat reflectance. Pada fungsi basis $B$, sejumlah 30 basis fungsi dari spektrum reflectance frekuensi rendah dipilih berdasarkan persentase energi terbesar dari koefisien komponen frekuensi rendah (Gambar 2).

Model polinomial dan filter wavelet digunakan pada setiap pengujian untuk mencari nilai reflectance rekonstruksi $r r$. Fungsi basis B dipilih kembali sejumlah terms pada model polinomial yang digunakan. Hal ini bertujuan untuk menyesuaikan dimensi matriks supaya operasi perkalian matriks dapat dilakukan. Filter wavelet yang digunakan pada transformasi wavelet adalah Haar, Daubechies $(N=5$ dan $N=10)$ dan symlet $(N=5$ dan $N=10)$. Level dekomposisi yang digunakan adalah level 1 sampai level 7. Filter Haar adalah filter dasar yang mempunyai vanishing moment $N$ terendah. Filter Daubechies dan symlet dikembangkan supaya wavelet mempunyai vanishing moment tertinggi. Wavelet symlet dikembangkan untuk membentuk wavelet yang lebih simetris. Hasil estimasi reflectance dari 10 daun jati belanda menggunakan set data 46 dan 276 ditunjukkan pada Tabel 2.

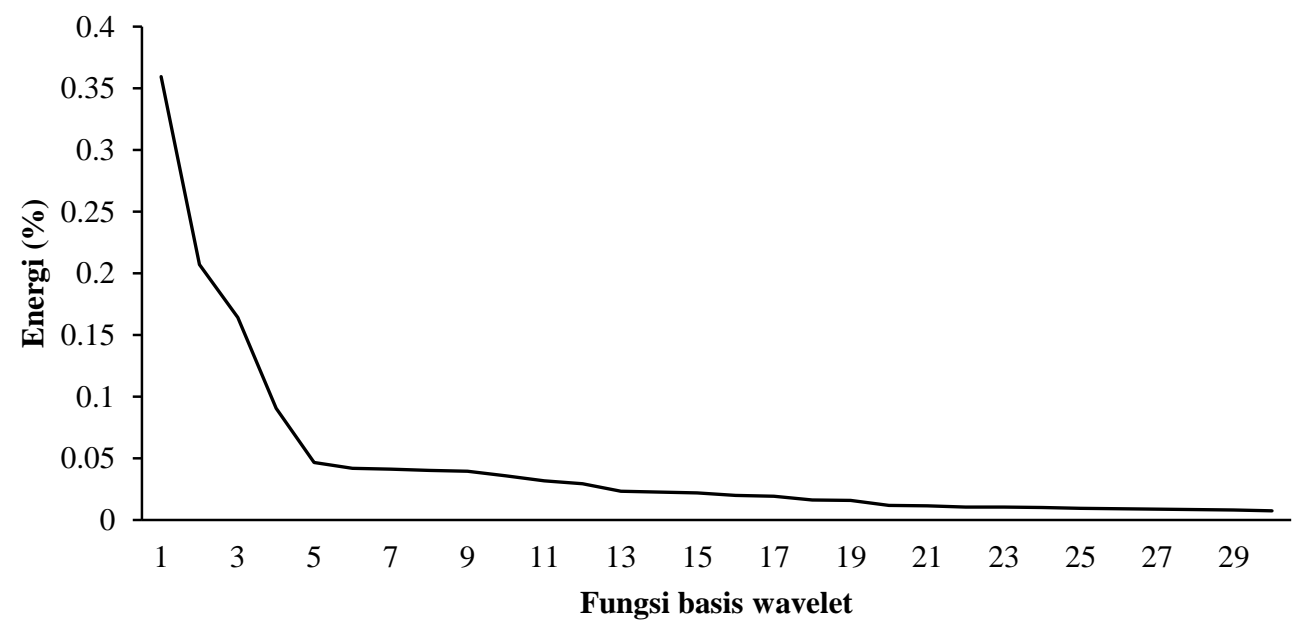

Gambar 3 Basis fungsi wavelet dengan energi terbesar (Haar level 3)

Tabel 2 Estimasi Reflectance daun jati belanda menggunakan set data 46 dan 276

\begin{tabular}{cccc}
\hline $\begin{array}{c}\text { Set data 46 } \\
\text { Wavelet }\end{array}$ & $\begin{array}{c}\text { Orde 1 } \\
\text { Haarlvl4 }\end{array}$ & $\begin{array}{c}\text { Orde 2 } \\
\text { db5lvl3 }\end{array}$ & $\begin{array}{c}\text { Orde 3 } \\
\text { db10lvl3 }\end{array}$ \\
\hline RMSE & 8.65 & 11.08 & 9.41 \\
GFC & 0.87 & 0.95 & 0.98 \\
\hline
\end{tabular}

\begin{tabular}{cccc}
\hline $\begin{array}{c}\text { Set data 276 } \\
\text { Wavelet }\end{array}$ & Orde 1 & Orde 2 & Orde 3 \\
\hline RMSE & 3.89 & 6.62 & 9.77 \\
GFC & 0.99 & 0.92 & 0.83 \\
\hline
\end{tabular}

Set data terbaik adalah set data 276 dengan penerapan transformasi wavelet Haar dekomposisi level 3 dan model polinomial orde 1 dengan nilai RMSE dan GFC sebesar 3.89 dan 0.99. Spektrum reflectance estimasi 10 daun jati belanda terbaik menggunakan set data 276 dapat dilihat pada Gambar 3. 


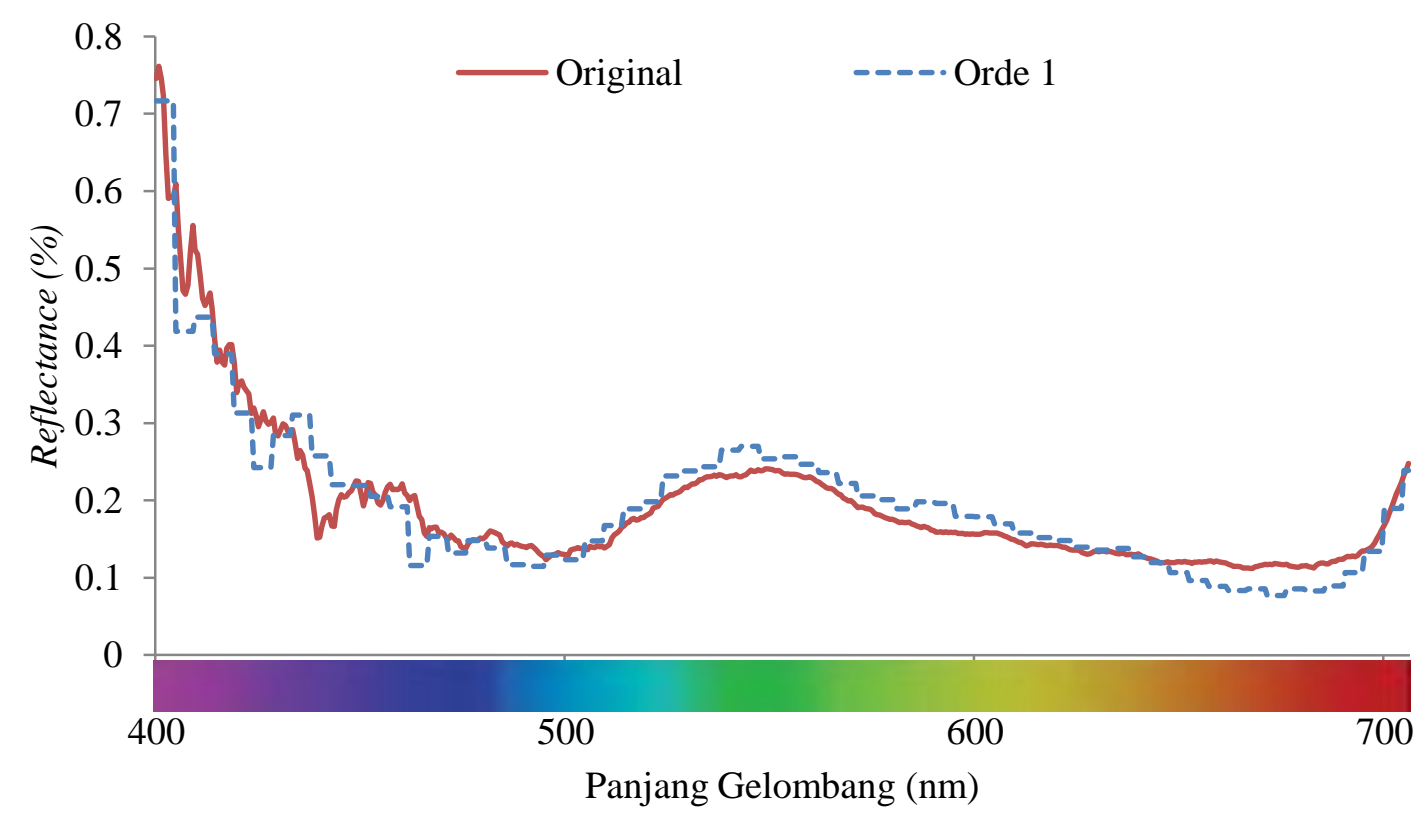

Gambar 4 Spektrum reflectance estimasi daun jati belanda menggunakan set data 276

Berdasarkan RMSE dan GFC, semakin banyak data yang digunakan maka model estimasi reflectance semakin baik (set data 276 lebih baik dari set data 46). Set data 276 adalah data asli dari proses akuisisi, sedangkan set data 46 dihasilkan dari proses rata-rata dari set data 276. Penggunaan model polinomial pada set data 276 menghasilkan RMSE dan GFC yang lebih stabil jika dibandingkan dengan set data 46. Hal ini dapat dilihat pada penggunaan set data 46, nilai RMSE model polinomial orde 2 lebih besar jika dibandingkan dengan orde 3 . Hal ini mengindikasikan penggunaan orde polinomial pada set data 46 menghasilkan error yang kurang stabil jika dibandingkan dengan penggunaan set data 276.

Penggunaan filter wavelet dan level dekomposisi menghasilkan estimasi reflectance yang berbeda pada setiap penggunaan orde polinomial. Transformasi wavelet memungkinkan penggunaan filter dan level dekomposisi yang lebih bervariasi. Penggunaan transformasi wavelet menghasilkan model estimasi reflectance yang lebih baik dari penggunaan transformasi Fourier. Penggunaan transformasi Fourier menghasilkan RMSE dan GFC dengan nilai 4.83 dan 0.96 (Lantana et al. 2014). Penerapan dekomposisi wavelet Haar level 3 menghasilkan RMSE dan GFC sebesar 3.89 dan 0.99. Perbedaan nilai RMSE adalah 0.94 yang relatif tidak terlalu besar. Penggunaan transformasi wavelet dan model polinomial menghasilkan GFC yang tergolong baik (Mansouri et al. 2008) dan lebih baik dari transformasi Fourier.

Pada rentang warna hijau (492-577 nm), sinyal original dan estimasi cenderung mirip dengan nilai error 0.0198. Hal ini mengindikasikan bahwa warna yang dihasilkan dari spektrum reflectance berkisar pada warna hijau. Warna daun jati belanda terletak di sekitar spektrum warna hijau, sama dengan warna daun yang diinterpretasikan oleh sistem penglihatan manusia.

\section{SIMPULAN}

Set data 276 daun tanaman obat, model polinomial orde 1 dan dekomposisi wavelet Haar level 3 menghasilkan model reflectance terbaik. Hasil evaluasi nilai RMSE dan GFC terbaik sebesar 3.89 dan 0.99 dengan kualitas kemiripan yang baik serta lebih baik dari penerapan model reflectance menggunakan transformasi Fourier. Penerapan transformasi wavelet memungkinkan penggunaan filter yang beragam sehingga memungkinkan pemilihan filter yang paling sesuai untuk model reflectance. 


\section{DAFTAR PUSTAKA}

Anuradha VE, Jaleel CA, Salem MA, Gomathinayagam M, Panneerselvam R. 2010. Plant growth regulators induced changes in antioxidant potential and andrographolide content in Andrographis paniculata Wall.ex Nees. Pesticide Biochemistry and Physiology. 98(2):312-316.

Choudhary N dan Sekhon BS. 2011. An overview of advances in the standardization of herbal drugs. J Pharm Educ Res. 2(2):55-70.

George CC, Vanderheyden PML, Solis PN, Pieters L, Shahat AA, Gupta MP., Vauquelin G, dan Vlietinck AJ. 2001. Biological screening of selected medicinal Panamanian plants by radioligand-binding techniques. Phytomedicine; 8(1): 59-70.

Herdiyeni Y, Azizah N, Heryanto R. 2014. Spectral Reflectance Estimation Based on Leaf Digital Image using Wiener Estimation for Sambiloto Leaf Age Prediction. The 8th International Conference on Information and Communication Technology and Systems.

Kushwaha SKS, Kushwaha Neelottama, Maurya N, Rai AK. 2010. Role of Markers in the Standardization of Herbal Drugs: A Review. Scholars research library; 2(1):225-229.

Lantana DA, Herdiyeni Y, Batubara I. 2014. Estimated Spectral Reflectances of jati belanda Leaf Using Fourier Transformation. TELKOMNIKA Indonesian Journal of Electrical Engineering. 12(9):6958-6964. DOI: 10.11591/telkomnika.v12i9.6404

Lee DTL dan Yamamoto A. 1994. Wavelet Analysis: Theory and Application. Hewlet-Packard Journal 1994. 44-52.

Mallat SG. 1989. A Theory for Multiresolution Signal Decomposition: The Wavelet Representation. IEEE Trans. Pattern Analysis and Machine Intelligence. 11(7):674-693.

Mansouri A, Sliwa T, Hardeberg JY, Voisin Y. 2008. Representation and Estimation of Spectral Reflectances Using Projection on PCA and Wavelet Bases. Wiley Periodical Inc. 33(6):485-493.

Sanjeevi S, Vani K. and Lakshmi K. 2001. Comparison of conventional and wavelet transform techniques for fusion of iris-1c liss-III and Panimages. 22nd Asian conference on remote sensing.

Singh SK, Jha SK. Chaudhary, Yadava RDS, Rai SB. 2010. Quality control of herbal medicines by using spectroscopic techniques and multivariate statistical analysis. Pharmaceut Biol. 48(2):134-141. DOI: $10.3109 / 1388020090305938$ 